Observatório de Inovação do Turismo

Revista Acadêmica

\title{
Turismo e processo de urbanização: desafios na preservação do patri- mônio natural e cultural
}

Tourism and the urbanization process: challenges in preserving natural and cultural heritage

Paulo de Assunção

\section{Resumo}

Neste artigo, visa-se a apresentar aspectos da interdependência entre o planejamento turístico e o planejamento urbano. Em se considerando o crescimento da atividade turística e das cidades, questões correlatas à necessidade da preservação do patrimônio natural e cultural emergem com intensidade nos estudos mais recentes. Por conseguinte, é importante analisar o processo que os seres humanos estabelecem em suas relações com o ambiente onde vivem e com o patrimônio herdado dos antepassados. A identidade do lugar passou a ser um elemento que diferencia cada vez mais as cidades e os produtos turísticos, sendo necessário entender a função pública do espaço urbano e da paisagem. Nesse sentido, procura-se destacar como ocorre a relação homem/natureza na cidade, enfatizando o jardim como ideia mítica de um paraíso perdido e o seu uso no contexto da atividade turística.

Palavras-chave: turismo, urbanização, preservação, patrimônio, cidades 


\section{Abstract:}

This article aims to present aspects of the interdependence between tourism planning and urban planning. Considering the growth of tourism and cities, issues related to the necessity of preserving the natural and cultural heritage is discussed with intensity in the recent studies. It is therefore important to examine the process as human beings establish their relations with the environment they live in and with the heritage received from the ancestors. The identity of the place came to be one element that differentiates more and more the cities and the tourist products, so it is necessary to understand the role of public space and landscape. In this sense, we seek to highlight how happens the relation human with the nature in the city, emphasizing the garden as a mythical idea of a paradise lost and its use in the context of tourism.

Key words: tourism, urbanization process, preservation, heritage, cities

Pensar o turismo, em especial num contexto urbano, não é algo fácil de ser empreendido, pois a maioria da população que vive nos grandes centros não consegue perceber os atrativos que as cidades oferecem. A proximidade, as contradições urbanas, o convívio diário, a circulação rápida, bem como uma sociedade complexa impedem, por vezes, os habitantes de questionarem a própria cultura e de aperceberem-se dos espaços verdes existentes e disponíveis (COELHO NETO, 1993, p. 48-56). Questionar por que se processou a formação da cidade e seu patrimônio, conhecer sua arquitetura, seus símbolos, suas manifestações artístico-culturais e compreender o fenômeno turístico parecem ser tão importantes quanto questionar a relação do homem com a natureza.

Turismo é caracterizado por uma estrutura transversal articulada a diversos setores da economia, ou seja, liga-se com diversos segmentos, interferindo e sendo afetado por eles, conferindo a essa atividade uma natureza multidimensional e multifacetada (ACERENZA, 2002). Dessa maneira, os governos têm guindado o turismo a um plano político, elaborando estratégias para melhorar a qualidade dos serviços nesse setor e dando novos rumos à utilização insuficiente do potencial turístico de algumas regiões. Doris Ruschmann, ao analisar a atividade turística sustentável, destaca que novas frentes do turismo podem ocasionar impactos ambientais, tornando o planejamento uma necessidade para o desenvolvimento equilibrado. A autora destaca que é

indispensável estimular o desenvolvimento harmonioso e coordenado do turismo; se não houver equilíbrio com o meio ambiente, a atividade turística comprometerá a própria sobrevivência. (RUSCHMANN, 1997, p. 49). 
O desenvolvimento econômico e a modernização das sociedades não foram homogêneos; assim, pode-se evidenciar que, em algumas áreas, a falta de sincronismo entre o desenvolvimento do turismo e a capacidade de carga gerou problemas graves. O fato é que o turismo causa impactos diretos na sociedade, sendo responsável por mudanças de estilo de vida e interferindo na identidade coletiva das cidades. Por decorrência, é necessário um planejamento urbano adequado que permita equacionar as vantagens e os riscos do desenvolvimento turístico. Observa Larkham:

O sistema de planejamento deve assegurar que o crescimento econômico seja capaz de prover a população com trabalho e moradia, de uma maneira que respeite a capacidade de seu meio ambiente e outros interesses conservacionistas (LARKHAM, 1996, p.12-13).

Deve-se ter em conta que o setor turístico, no decorrer de seu processo evolutivo, demonstra uma capacidade de mutação e adaptação às novas demandas e exigências da sociedade, atendendo aos mais distintos interesses. Isso implica considerar os patrimônios culturais e naturais como elementos estratégicos de grandes projetos turísticos, fatores que cada vez mais se apresentam como fundamentais. A nova ordenação do mundo do trabalho, a redução das jornadas de trabalho, o aumento do tempo livre, a melhoria do nível de vida da população em geral e a globalização das comunicações e dos transportes são elementos importantes a serem considerados quando se discute as alterações sofridas pela atividade turística.

Muitas cidades tiveram um crescimento marcado pela ocupação não planejada, fruto de realidades socioeconômicas desiguais, o que permitiu um processo de urbanização pouco homogêneo, o qual é identificável nas diferentes espacializações encontradas no Brasil e em outras partes do mundo. A degradação do espaço público é também um reflexo da fragmentação das identidades e da perda de valores da cidadania. Como bem salienta Elisabeth Telfer, o homem exprime-se socialmente em espaços públicos. É nesse espaço que os seres humanos revelam ligação com a sociedade, compartilhando culturas, saberes e normas (TELFER, 2004, p. 12). Margarita Barretto, por sua vez, ao analisar as transgressões dos espaços públicos, ressalta como essas áreas têm sido associadas à insegurança urbana, ao aumento dos índices de violência e à falta de atenção do poder instituído (LE GOFF, 1988). Para a autora, é fundamental "repensar os grandes conglomerados urbanos, partindo de um planejamento que leve em conta as necessidades humanas" (BARRETTO, 1999, p. 52).

Nos grandes centros urbanos, como São Paulo e Rio de Janeiro, entre outras capitais mundiais, as políticas urbanas empreendidas no decorrer do século $X X$, momento em que o desenvolvimento das cidades se acelerou, revelam que as espacializações foram desiguais e contrastantes. Vários fatores influenciaram nesse processo: especulação imobiliária, falta de 
planejamento e controle das políticas públicas, entre outros. Nessa cadência, o desenvolvimento capitalista contribuiu para dessacralizar a natureza, criando espaços hiper-reais para atender ao imaginário do homem contemporâneo.

No caso de São Paulo e do Rio de Janeiro, enquanto em algumas regiões evidenciam-se infraestruturas e equipamentos urbanos adequados, em outras, prepondera a ausência deles, não atingindo as condições satisfatórias para os cidadãos que lá habitam. A precariedade do abastecimento de água, do saneamento básico, da iluminação pública, a falta de acesso às redes de transporte coletivo, a falta de segurança são exemplos claros das diferenças urbanas, reflexo de desigualdades sociais mais profundas e da falta de um planejamento estratégico mais atento aos problemas sociais (SIMÃO, 2001, p. 43).

O processo de urbanização desenfreado que se intensificou no decorrer do século $X X$, principalmente nas últimas décadas, foi marcado por um desenvolvimento contraditório e incongruente, influenciado pela especulação imobiliária, ganhando contornos mais acentuados com a distribuição desigual da renda e o desemprego, na maioria dos países (BOSQUET, 1980). Como bem ressaltou Fernando Chueca Goitia:

A transformação é incongruente porque o ritmo de crescimento é muito superior à capacidade de previsão das autoridades, de assimilação dos problemas, de obtenção de créditos suficientes para levar a cabo as reformas de fundo, que são as que ajudam a criar novas estruturas eficazes, sem malbaratar o dinheiro em reformas eventuais e de circunstância (GOITIA, 2003, p. 170).

Deve-se ainda considerar que o intenso fluxo migratório para a cidade contribui para a deterioração de antigos bairros proletários e para a formação de novos espaços, marcados pela segregação espacial. A cidade, como forma civilizada de convívio coletivo, apresentou-se como a expressão somatória da existência, seja física, seja espiritual, dos cidadãos que a habitavam. As diferenças entre o meio rural, onde a dispersão prepondera, e o meio urbano, onde a concentração vigora, são evidentes. A paisagem indica diferenças claras e contrastantes e permite identificar diferentes categorias estéticas do espaço. Cada cidade apresenta um ambiente natural específico, em razão da localização, do crescimento e da história moldada pela ação humana.

O crescimento desordenado permitiu que, progressivamente, se fossem apagando os traços da natureza e do patrimônio construído nos séculos anteriores, permitindo que somente alguns vestígios sobrevivessem. Restam, pois, apenas fragmentos da natureza e da cultura material de um passado esquecido e, por vezes, desprezado. Descompassos que interferem diretamente na vida da cidade e em sua imagem e que levam a discutir a questão dos patrimônios naturais e culturais e a possibilidade do uso pelo turismo. 
$\mathrm{Na}$ cidade, em seu processo de evolução, acabou-se por privilegiar alguns aspectos estéticos e cenográficos, deixando as dimensões histórico-culturais para um segundo plano, o que acarretou um prejuízo à memória social. A lógica do capitalismo em sua velocidade absurda fez que o desenvolvimento e a exploração do espaço desprezassem o que Eduardo Yázigi chama de a "alma do lugar" (YÁZIGI, 2002).

A "alma do lugar" implica a consideração da natureza e a intervenção que os seres humanos fizeram nela para poder sobreviver no decorrer dos séculos. Os desmedidos interesses financeiros de alguns projetos imobiliários e turísticos colocaram em risco o uso do espaço coletivo. A exploração de cidades e regiões por interesses turísticos, sem um planejamento adequado, fez que ocorresse um processo acentuado de descaracterização arquitetônica, causando prejuízos significativos ao patrimônio material. Quando se voltam os olhos para o espaço natural, percebe-se que o dano é ainda maior, pois, na maioria das vezes, a paisagem e o patrimônio natural não foram respeitados. Destruiu-se a natureza que outrora dominava o espaço para que se urdisse um tecido urbano. Principalmente nas cidades, os homens tentaram controlar e apreender a natureza em verdadeiros "jardins", enquanto uma massa de edifícios era construída. Não se pode esquecer que o crescimento pressupõe um planejamento adequado, o que implica afirmar que os interesses econômicos devem estar em consonância com o bem-estar social e com o meio ambiente. Como afirma Doris Ruschmann,

o planejamento é fundamental para o desenvolvimento turístico equilibrado e em harmonia com os recursos físicos, culturais e sociais das regiões receptoras, evitando, assim, que o turismo destrua as bases que o fazem existir.

Para Ruschmann, o meio ambiente constitui um elemento fundamental do turismo. Não se pode negar que a motivação de muitos turistas é a possibilidade de contato com a natureza. Muitos alimentam o desejo de entrar em contato com a natureza e, por decorrência, a ideia de proteção dos espaços naturais e a existência de serviços e equipamentos oferecidos passam a ser alvo de discussão. Vale lembrar que o turismo pode causar impactos à natureza e à cidade, promovendo mudanças e alterando parâmetros (RUSCHMANN, 1997, p. 10).

Cada vez mais, nas cidades, é preciso oferecer aos habitantes espaços de convivência, integração e lazer que garantam uma qualidade de vida conveniente. Nesse sentido, a discussão dos usos dos espaços faz parte de um processo importante na construção da consciência coletiva. Jacques Le Goff, em sua obra Por amor às cidades, analisa o papel das cidades, considerando os impactos que a concentração urbana pode causar. Para ele, é fundamental que os homens se apercebam da necessidade de recuperar-se a função pública das cidades, pois são palcos para o 
exercício da cidadania, espaços de convivência e de cultura, lugares de formação e informação, locais de criatividade e de diálogo. Como bem destaca o autor, a cidade é portadora de uma ideia de inovação e criação em sua função cultural. Como local de circulação, na cidade, pressupõe-se um "novo sistema de valores nascido da prática laboriosa e criadora do trabalho, do gosto pelo negócio e pelo dinheiro" (LE GOFF, 1988, p. 28). Nessa linha de pensamento, o estudioso entende que a cidade do século XXI se recria e deve ser capaz de "conceber novos encontros que irão renovar sua sedução" (LE GOFF, 1988, p. 163).

Considera-se que a linguagem arquitetônica da cidade é marcada por uma multiplicidade de nuances em razão de seu processo histórico e da disposição que os elementos internos e externos estabeleceram entre si. Os esquemas volumétricos das edificações e as relações entre eles nem sempre constituem uma situação harmônica, dando à composição do conjunto uma nuance particular na medida em que os espaços preenchidos se contrapõem aos espaços vazios e, nestes, há possibilidade de surgir pequenas brechas para a natureza. A cidade é um ser dinâmico e mutante que se recria com novas roupagens, novas leituras, inclusive do mundo natural.

A imagem da natureza é carregada de crenças, valores, mitos e símbolos que a sociedade construiu no decorrer dos séculos. Para o pensamento cristão ocidental, a ordem do meio natural - ou do Universo criado - esteve diretamente ligada à estruturação de uma sociedade ordenada. Entendeu-se o mundo natural como decorrência do ato autoritário primordial do Criador, que instaurou a existência do meio natural. A criação do Mundo por Deus, em sua diversidade de espécies, tinha como objetivo dar condições para a existência humana: de fato um ato planejado.

A natureza atendia à necessidade de sobrevivência humana, cabendo aos homens preservá-la, uma vez que Deus colocou suas criaturas num "paraíso de delícias, para que o cultivasse e guardasse"1. Conforme observa Feuerbach, o princípio supremo do judaísmo, que é o utilitarismo, identificava os elementos naturais como "um mero meio para o fim do egoísmo um mero objeto da vontade". Dessa forma, o mundo natural para os hebreus é "o produto de uma palavra ditatorial, de um imperativo categórico, de um decreto mágico" (FEUERBACH, 1988, p. 156).

A quebra da ordem ideal - ou do convívio harmonioso -, que os seres humanos compartilhavam com a natureza, rompeu-se logo após o pecado original (FRANCO JR., 1992, p. 23). Com a expulsão do Paraíso (Jardim do Éden), permitiu-se ao homem vislumbrar que a Providência Divina tinha o controle dos elementos naturais e poderia agir com fins punitivos, na medida em que interviria para causar a degeneração da terra. O pecado original estabeleceu a consciência humana na distinção entre o Homem e a Natureza. O homem era expulso do Paraíso e lançado num mundo natural onde havia a preponderância de um meio selvagem, não cultivado, portanto, negativo, com o qual teria que guerrear para sobreviver: a relação de harmonia deixava de existir, sendo substituída pelo temor (HEINBERG, 1991, p. 5). A natureza tornou-se uma barreira hostil aos desejos 
de sobreviver. O poder sobre o mundo natural significava, em outras palavras, uma luta contínua contra o meio selvagem, para que este fosse dominado e conquistado, ou seja, cultivado, residindo nesse ato boa parte do engenho humano (TURNER, 1990, p. 47). Revestida de um papel duplo, a concepção de natureza oscilou entre a fonte da vida e a possibilidade da morte, alvo de uma leitura mais utilitarista do que filosófica da natureza; como salienta Feuerbach,

o utilismo, que nada mais contém, nada mais expressa além do imperativo de não se fazer da natureza um objeto de pensamento, da contemplação, mas sim da utilização, do aproveitamento (FEUERBA-

$\mathrm{CH}, 1988$, p. 158).

O homem jamais esqueceu sua estada no Éden. Banido dali, buscou, nos períodos seguintes, recuperá-lo ou redescobri-lo: conquistar ou reconstruir um novo jardim para si. ${ }^{2}$ Nesse sentido, o jardim configurou-se como um símbolo da esperança e da salvação: um paraíso terrestre ou "um paraíso de delícias"3 - imagem idealizada, que passou a ser constante na imagética ocidental.

O ambiente natural modificado pela atuação humana permitiu a construção de uma obra permanente que é a paisagem em que vivemos (LEVI-STRAUSS, 1996, p. 322-323). Em específico, a paisagem urbana constrói-se lentamente com base na ocupação dos espaços livres, que vão sendo incorporados à cidade contemporânea, alterando marcos e referenciais que implicam a alteração dos referenciais (LANDIM, 2004, p. 28-39). Pode-se afirmar que o ser humano empreendeu ações no mundo natural para atender às necessidades e inquietudes de sua existência. No decorrer dos anos, ele destruiu, consciente ou inconscientemente, a natureza para suprir sua existência. Paulatinamente, conduzia-se a natureza ao suicídio, e o homem distanciava-se da interação íntima que com ela tinha, principalmente nas metrópoles.

A paisagem urbana passou a ser a composição dos espaços construídos com os espaços livres. Como nos últimos anos, o crescimento das cidades foi intenso, o espaço construído avançou sobre os espaços livres, promovendo uma agressiva transformação da paisagem natural. Conforme observa Silvio Soares Macedo, a paisagem é

\footnotetext{
${ }^{2}$ Conforme observa Heinberg, "o mundo ocidental tem uma herança de pelo menos cinco tradições, aparentemente independentes, de um Paraíso original: o Jardim do Éden Hebraico, o Dilmun sumeriano, o Jardim iraniano de Yima, Tep Zepi egípcio e a Idade de Ouro grega". Ressalte-se que o termo "Éden" significa para os sumerianos "planície fértil", sentido similar àquele utilizado na Bíblia. Para uma análise mais profunda sobre o tema ver HEINBERG, Richard, op. cit., p. 50-53.

${ }^{3}$ Gên. 2,8-14. Conforme observa Heinberg, "o mundo ocidental tem uma herança de pelo menos cinco tradições, aparentemente independentes, de um Paraíso original: o Jardim do Éden Hebraico, o Dilmun sumeriano, o Jardim iraniano de Yima, Tep Zepi egípcio e a Idade de Ouro grega". Ressalte-se que o termo "Éden" significa para os sumerianos "planície fértil", sentido similar àquele utilizado na Bíblia. Para uma análise mais profunda sobre o tema ver HEINBERG, Richard, op. cit., p. 50-53.
}

${ }^{3}$ Gên. 2,8-14. 
a expressão morfológica de um determinado tempo, do proces-

so constante de ação dos seres vivos sobre os diversos pontos do planeta associado ao movimento contínuo das diferentes estruturas geológicas e águas (MACEDO, 1994, p. 54).

O espaço físico natural recebeu a intervenção humana numa dinâmica de destruir e construir, movimento nem sempre perceptível aos olhos humanos, habituados a transformações rápidas. A presença de elementos naturais no ambiente urbano não significou a manutenção da natureza em seu estado primitivo. Os elementos naturais que sobreviveram eram de fato produtos de uma paisagem natural - ao mesmo tempo artificial - produzida pelo homem. Uma recriação concebida para a sedução.

Os jardins ilustram essa relação do homem com a natureza. Na maioria deles, a natureza aparece dominada nas mais diversas formas. Os jardins monumentais constituem cenários para a vida humana. A cidade fez que o homem se distanciasse da relação mais profunda com a natureza, criando imagens edênicas que remetiam ao Paraíso perdido.

O homem procurou capturar fragmentos da natureza no jardim, a fim de preservar um sistema ecológico reduzido, principalmente sedutor. De certa maneira, o jardim constitui o lugar possível da natureza no espaço da cidade: lugar de reunificação do homem e das coisas naturais. O jardim é, pois, a natureza permitida pelo gesto humano construtivo. Configuração fabricada da natureza pelas práticas humanas, ou seja, o resultado da apropriação e transformação do meio natural pelo homem. O jardim pode ser visto também como a resistência do mundo natural aos enfrentamentos que a sociedade contemporânea impôs. Ao modelar-se a cidade, definiam-se as paisagens e nem sempre o senso estético privilegiou a natureza. As áreas verdes são preservadas como pedaços do mundo natural. Essa relação de homem/natureza foi denominada por Moscovici, como "naturalismo-relativo", ou seja, o movimento de proteger a natureza implica a segregação do espaço natural em pequenos fragmentos, de forma que o homem moderno possa admirá-la (MOSCOVICl, 1977).

O jardim, lugar de encontro e reencontro, permite a fuga da vida caótica das cidades e, por vezes, constitui-se como um refúgio natural. A paisagem moderna é paradigmática na relação arquitetura/natureza, em sua relação de continuidade e descontinuidade. O jardim é a forma ordenada da natureza possível no meio urbano. A desordem do mundo natural é desconcertante para a cidade, onde, rapidamente, destruiu-se a natureza para atender às necessidades de sobrevivência. O jardim, imitação da natureza, triunfou nos limites do possível nas áreas urbanas. Na realidade, na cidade contemporânea, permitiu-se que jardins se transformassem em cenas da natureza, cercadas de uma arquitetura que revela o alto grau de desenvolvimento tecnológico da sociedade. Tal como o turista, o morador das cercanias de um jardim público pode contemplar, por meio do vidro de suas janelas, a natureza domada, pronta para consumo e deleite estético. 
O jardim emerge, assim, no âmbito da cidade, como um lugar lúdico de prazer que remete à união com um tempo perdido. Nesse sentido, o homem adapta o mundo natural a uma realidade que atenda a seus desejos. O jardim é, assim, uma cópia cultural da natureza, ou seja, a natureza desnaturalizada, na qual o homem procura encontrar por vezes o paradigma perdido. Da mesma forma, os jardins se afirmaram como espaços de lazer e de encontro, principalmente nas cidades onde a falta de estrutura é acentuada. São espaços, portanto, que cumprem uma importante função social e que constituem marcos de identidade local. Conforme observa Pompeu de Carvalho, o lugar faz parte da essência humana. Nesse sentido, o turismo, é visto

como aquela atividade em que se processa e se intensifica a realização de uma essência humana, de uma realização do homem com a humanidade através de espaços-tempos mais amplos, mais diversos (CARVALHO, 2002, p. 109).

Essa situação limítrofe do jardim, como um lugar cultural e natural, permite discutir como o homem vivencia essa interação. Nas cidades modernas, onde cada vez mais a dinâmica urbana é frenética, o jardim passou a ser um lugar onde é possível ter uma tranquilidade pouco comum. Uma composição natural criada pelo homem, para que possa usufruir do espaço como local de interação com o momento primordial. Espaço que pode ser o lugar do tudo e do nada.

O jardim permite que o ser humano usufrua de um contato com a natureza no espaço da urbanidade. Prazer com que alguns moradores dos grandes centros urbanos podem contar, bem como turistas que encontram no local uma estrutura de relação dos habitantes com o mundo natural. As grandes metrópoles da América são marcadas pelo crescimento vertiginoso e caótico, mesclando modernidade com problemas urbanos antigos. A alta concentração populacional contrasta com a falta de espaços abertos, como praças e jardins. O avanço das metrópoles fez que a incorporação de áreas verdes fosse feita de forma irregular, não levando em consideração os ecossistemas locais. Sem dúvida, a preservação de jardins e áreas verdes, nos grandes centros urbanos, depende de políticas governamentais de preservação e recuperação do meio ambiente. Dessa forma, sem medidas políticas e administrativas não é possível preservar.

$\mathrm{Na}$ atualidade, observa-se que o desenho urbano tem sofrido variações marcantes, causando preocupações que não preponderam. O processo de construção da cidade revela que o caráter artístico sofreu um empobrecimento estético. A uniformização, tendência observada nas últimas décadas, revela um olhar voltado para a repetição de modelos idealizados, na maioria das vezes, individualistas e segregacionistas.

Pode-se afirmar que o homem procura a harmonia discreta de sua identidade no meio natural. Nos jardins, os valores mais nobres podem ser atingidos. As oposições podem ser harmonizadas. 
O homem pode atingir sua totalidade e perceber seus limites. A cidade, suas construções e áreas verdes, em especial os jardins, constituem elementos-chave para a compreensão da cultura de uma sociedade. A relação do espaço habitado com o espaço natural, de maneira equilibrada, permite questionar como o homem é capaz de harmonizar o crescimento material com a necessidade de preservação: questões que são postas por moradores e visitantes da cidade.

Espectador da natureza, o homem encontra o equilíbrio no mundo natural, e esse universo pode constituir-se em elemento útil para o turismo. A procura por locais paradisíacos constitui hoje uma parcela importante da atividade turística mundial. O homem alimenta a utopia de poder contemplar e interagir com uma paisagem natural, mesmo que seja uma paisagem normalizada. A imagem do Jardim do Éden faz-se ainda presente no horizonte mental dos turistas contemporâneos; nesse movimento, a busca por espaços naturais e jardins demonstra que o homem procura o reencontro com a plenitude da vida.

Os impactos da atividade turística sobre o meio ambiente são muitos e podem determinar a prosperidade ou não do setor. Além disso, um planejamento inadequado pode vir a comprometer a existência de uma cidade, quando não se considera o meio ambiente, pois dele provêm os recursos necessários para o desenvolvimento da sociedade. A ideia de fazer bom uso do espaço faz parte da política de conservação dos recursos para que todos possam desfrutar o hoje e o amanhã. O desenvolvimento turístico sem degradação ou esgotamento dos recursos é possível, desde que o planejamento urbano tenha sido concebido de forma adequada.

Nos dias atuais, a valorização de bens, que representam referências culturais ou naturais, faz a diferença, diante de um mundo em que a padronização está cada vez mais presente. A cidade de Curitiba, capital do estado do Paraná, é um dos exemplos significativos no que tange à questão de pensar áreas ociosas e áreas de lazer. A administração pública, por meio de planejamentos urbanos, conseguiu resultados favoráveis nos espaços desocupados, transformando-os em área de lazer, ao mesmo tempo em que valorizou a cultura dos povos que formaram a cidade.

O planejamento urbano de Curitiba, seguindo princípios modernistas, fez que, no crescimento da cidade, se levasse em conta o lugar e as forças dos agentes envolvidos. Dessa maneira, jardins e parques foram concebidos a fim de reforçar o caráter comunitário de tais espaços. Além disso, áreas foram criadas partindo do pressuposto de que usuários, moradores e visitantes, seriam responsáveis pela conservação do local. Ao estado cabia a manutenção dos limites físicos e dos equipamentos públicos de fins culturais ou de outros monumentos de caráter simbólico, cujo sentido era servir de foco de atração para a comunidade e para os turistas.

Uma ocupação verticalizada prolifera, atendendo à demanda imobiliária no entorno do Jardim Botânico de Curitiba. Concomitantemente, o espaço verde do Jardim constitui-se como um atra-

${ }^{3}$ Entrevista concedida a Diego Andrade Gomes pelo prefeito e pela secretária de Educação do município de Vera Cruz, em 22 nov. 2010. 
tivo turístico de Curitiba, verdadeiro cartão-postal de uma cidade onde o planejamento urbano tem obtido resultados satisfatórios. Enfim, é possível afirmar que o caso de Curitiba atende ao que Doris Ruschmann chamou de uma relação sustentável do turismo nos espaços naturais. Destaca a autora:

Uma boa gestão territorial envolve o reconhecimento e o estabelecimento dos limites que não podem ser ultrapassados em nome do desenvolvimento. A nova tendência do turismo nos espaços naturais associa-se, principalmente, à rarefação dos espaços pouco poluídos e dos preservados. Inversamente, quando uma localidade turística natural passa a ser massivamente frequentada, ela passa a ter os equipamentos para atender a essa demanda e perde sua característica de turismo natural. O valor ecológico está associado ao valor de sua paisagem e, consequentemente, à sua atratividade turística

(RUSCHMANN, 1997, p. 79-80).

Esse resultado advém de políticas públicas que consideraram os vários atores sociais que compõem a cidade. Adequou-se o modelo turístico adotado ao perfil da cidade, tendo como atrativo a relação equilibrada entre o espaço construído e o espaço natural. Um modelo de desenvolvimento turístico que obteve êxito na medida em que a percepção da cidade foi considerada tanto para moradores, quanto para turistas. A cidade passou a ser um cenário que proporciona vivências lúdicas, considerando-se o movimento da cidade e a complexidade urbana e sociocultural. Além disso, não se pode deixar de destacar que um planejamento que levou em conta o turismo sustentável permitiu a valorização da natureza e, por meio dela, o reforço à cultura e às tradições daquela cidade.

No caso de Curitiba, o que se observa é que o nível de organização dos serviços públicos urbanos oferecidos à população e aos visitantes atende às necessidades dos moradores e do turismo. Os benefícios de um contato próximo com a natureza são somados a outros, como o de geração de emprego, espaços de lazer, conservação ambiental, entre outros aspectos positivos.

Mediante essas evidências, entende-se que se faz premente a discussão sobre a reconstrução dos espaços e da relação do espaço habitado com a natureza. É preciso, então, pensar a viabilidade da transformação urbana, de maneira que ocorra a participação da comunidade e que se reforce o sentimento de identidade, permitindo a continuidade dos valores culturais para gerações seguintes. Abdicar de um comportamento consumista e capitalista que gere impactos nocivos para todos deve ser o objetivo da coletividade. ${ }^{4}$

\footnotetext{
${ }^{4}$ A Agenda-21, documento produzido na Conferência Geral das Nações Unidas sobre o Meio Ambiente e o Desenvolvimento - RIO-92 - , reafirmando a Declaração de Estocolmo-72, contribui sobremaneira e conclui com esta exposição: “O melhor modo de tratar as questões ambientais é a participação de todos os cidadãos interessados no nível correspondente. No plano nacional, qualquer pessoa deverá ter acesso adequado à informação sobre o meio ambiente de que disponham as autoridades públicas, inclusive a informação sobre os materiais e as atividades que ocasionem perigo a suas comunidades, assim como a oportunidade de participar nos processos de adoção de decisões. Os estados deverão facilitar e incentivar a sensibilização e a participação da população, colocando a informação à disposição de todos" (RIO-92).
} 
Em suma, pode-se afirmar que é fundamental considerar o turismo como uma fonte importante de cultura. É preciso pensar e ampliar os estudos que colocam em evidência a relação do turismo com a conservação dos patrimônios naturais e culturais. Não se pode esquecer de que a cidade e os jardins nos centros urbanos podem ser alvos de leituras multidisciplinares, envolvendo questões políticas, econômicas, sociológicas, técnicas, ecológicas, históricas, entre outros aspectos. Por conseguinte, é fundamental abordar as propostas e as estratégias políticas apropriadas para que o turismo tenha possibilidade de desenvolver-se de maneira adequada.

Pensar a conservação de recursos naturais e sua relação com o desenvolvimento da cidade e da atividade turística permite tornar compatível a utilização dos ambientes naturais de forma regrada. Somente por meio de um sistema integrado é que será possível pensar o desenvolvimento sustentável. ${ }^{5} \mathrm{O}$ planejamento adequado do espaço, nos aspectos arquitetônico, urbanístico e paisagístico, interfere nas práticas de um turismo responsável e qualificado. Sem dúvida, a continuidade dos jardins do mundo só será possível se for desenvolvida uma atitude de responsabilidades social, ecológica e turística.

Se por um lado o turismo pode garantir recursos abundantes imediatamente, por outro, é preciso pensá-lo de maneira apropriada. Por outro lado, deve-se salientar que o jardim permite a melhoria da qualidade de vida na área urbana. Dessa maneira, os grandes empreendimentos imobiliários, nos últimos anos, procuraram adquirir e efetivar projetos arquitetônicos no entorno de áreas verdes, em especial dos jardins. Nesses locais, preservados por legislação municipal que impede a alteração de uso, fez que edifícios construídos no entorno adquirissem valores mais elevados, altamente lucrativos para a indústria da construção civil. O jardim constitui, pois, uma paisagem acalentadora em meio a uma cidade onde a somatória de construções cria um aspecto desolador e, por vezes, caótico. A exploração inadequada da natureza deu ensejo ao esgotamento de alguns recursos necessários à sobrevivência humana. Após um longo período de exploração, o ser humano apercebeu-se de que a própria natureza tem limites e que a destruição pode causar danos irreversíveis.

Dessa maneira, pensar a interferência humana na natureza, seja para o espaço da habitação, seja para o turismo, implica discutir de forma coerente a ação humana com o mundo natural, ou seja, discutir a própria essência do desenvolvimento sustentável num processo de mudança de valores. O ser humano corre o risco de levar uma vida toda na falsa ilusão de dominar o mundo natural e pensar que é capaz de conter espaços naturais possíveis nos centros urbanos. Contudo a inexorável dinâmica da vida faz que o homem, após sua finitude biológica, volte a ser contido, dominado pela natureza, dando início a um novo ciclo.

${ }^{5} \mathrm{O}$ termo sustentável tem sido utilizado para expressar a ideia de os seres humanos necessitarem viver conforme os limites determinados pela natureza, não lhe causando danos. Em outras palavras, pode-se dizer que o termo sustentável leva ao entendimento dos limites em que o meio ambiente aceita transformações. 


\section{Referências}

ACERENZA, Miguel Angel. Administração do turismo. Bauru: EDUSC, 2002, vols. 1 e 2.

ADAMS, Betina. Preservação urbana: gestão e resgate de uma história. Florianópolis: Editora da UFSC, 2002

AMORIM FILHO, O. B. O contexto teórico do desenvolvimento dos estudos humanísticos e perceptivos na geografia. In: ; CARTER H.; KOHLSDORF M. E. Percepção am-

biental: contexto teórico e aplicações ao tema urbano. Belo Horizonte: Departamento de Geografia/Instituto de Geociências: UFMG, 1987, p. 13 (Publicação especial, 5).

ANDRADE, José Vicente de. Turismo, fundamentos e dimensões. São Paulo: Ática, 1992.

ANDRANOVICH, Gregory D.; RIPOSA, Gerry. Doing urban research. London: Sage, 1993.

ARAÚJO, Silvana Miceli de. Artifício e autenticidade: o turismo como experiência antropológica. In: BANDUCCI JR., Álvaro; BARRETTO, Margarita (orgs.). Turismo e identidade local: uma visão antropológica. Campinas-São Paulo: Papirus, 2001.

ASSUNÇÃO, Paulo de. O patrimônio. São Paulo: Loyola, 2003.

BALANZÁ, Isabel Milio; NADAL, Mônica Cabo. Marketing e comercialização de produtos turísticos. São Paulo: Pioneira Thomson Learning, 2003.

BANDUCCI JR., Álvaro; BARRETTO, Margarita (orgs.). Turismo e identidade local: uma visão antropológica. Campinas-São Paulo: Papirus, 2001.

BARBOSA, Ycarim Melgaço. O despertar do turismo: um olhar crítico sobre os não lugares. São Paulo: Aleph, 2001.

BARRETTO, Margarita. Manual de iniciação ao estudo do turismo. Campinas-SP: Papirus, 1999. Turismo e legado cultural. Campinas: Papirus, 2000.

BENI, Mário. Análise estrutural do turismo. São Paulo: SENAC, 1998.

BERGER, P. L.; LUCKMANN, T. A construção social da realidade. Rio de Janeiro: Vozes, 1999. BOMFIM, N. R. O conceito de patrimônio numa perspectiva multidisciplinar: contribuições para uma mudança de enfoque. Revista Turismo \& Desenvolvimento, São Paulo, vol. 5, n.01, p. 27-35, 2006.

BONIFACE, Priscila. Managing Quality Cultural Tourism. London: Routledge, 1995.

BOSQUET, Michel. Ecología y libertad. Barcelona: Editorial Gustavo Gilli, 1980.

BOUINOT, J.; BERMILS, B. La gestion stratégique des villes. Paris: A. Colin, 1995.

BOULLON, R. C. Planificación del espacio turístico. México: Trillas, 1988.

BOYER, Marc. Histoire du tourisme de masse. Paris: PUF, 1999.

BURNS, Peter M. Turismo e antropologia: uma introdução. Trad. Dayse Batista. São Paulo: Chronos, 2002. 
CANCLINI, N. Garcia. Culturas híbridas: estratégias para entrar e sair da modernidade. São Paulo: Edusp, 1998.

O patrimônio cultural e a construção imaginária do nacional. Revista do Patrimônio Histórico e Artístico Nacional, Rio de Janeiro, n.ำ23, p. 94-115, 1994.

CARVALHO, Pompeu F. de. Patrimônio cultural e artístico nas cidades paulistas: a construção do lugar. In: YAZIGI et. al. (orgs.). Turismo, espaço, paisagem e cultura. São Paulo: Hucitec, 2002, p. 100-113.

CASTRO, Sonia Rabello. O estado na preservação de bens culturais: o tombamento. Rio de Janeiro: Renovar, 1991.

CHAMBERS, Erve. Tourism and Culture. Albany: State University of New York Press, 1997.

CHOAY, F. A alegoria do patrimônio. São Paulo: Estação Liberdade/Unesp, 2001.

COELHO NETO, J. Teixeira. A construção do sentido na arquitetura. São Paulo: Perspectiva, 1993. COLLOT, Michel. Pontos de vista sobre a percepção das paisagens. Boletim de Geografia Teorética, Rio Claro-São Paulo, vol. 20, n.o, p. 21-32, 1990.

COOPER, Chris et al. Turismo, princípios e práticas. Porto Alegre: Bookman, 2001.

CORREA, Roberto Lobato. O espaço urbano. Rio de Janeiro: Ática, 2003.

DENCKER, Ada de Freitas Manetti. Métodos e técnicas de pesquisa em turismo. 2. ed. São Paulo: Futura, 1998.

DIAS, Reinaldo. Planejamento do turismo: política e desenvolvimento do turismo no Brasil. São Paulo: Atlas, 2003.

FERRARA, Lucrécia D'Aléssio. Os significados urbanos. São Paulo: Edusp, 2000.

FEUERBACH, Ludwig. A essência do cristianismo. Trad. José da Silva Brandão. Campinas: Papirus, 1988.

FRANCO Jr., Hilário. Utopias medievais. São Paulo: Brasiliense, 1992.

FÚSTER, L. F. ¿Una nueva geografía? In: Geografía general del turismo de masas. Madrid-España: Alianza Editorial, 1991, p. 9-46.

GOITIA, Fernando Chueca. Breve história do urbanismo. Lisboa: Presença, 2003.

HEIMSTRA, Norman W.; McFARLING, Leslie H. Psicologia ambiental. São Paulo: Edusp/ EPU, 1978.

HEINBERG, Richard. Memórias e visões do paraíso. Trad. Octávio Mendes Cajado. Rio de Janeiro: Campus, 1991.

KRIPPENDORF, Jost. Sociologia do turismo: para uma nova compreensão do lazer e das viagens. 3. ed. rev. São Paulo: Aleph, 2003.

LAKOFF, G.; Johnson, M. Les métaphores dans la vie quotidienne. Paris: Minuit, 1990.

LANDIM, Paula. O desenho de paisagens urbanas: as cidades do interior paulista. São Paulo: UNESP, 2004. 
LAPLANTE, M. Le patrimoine en tant qu'attraction touristique: histoire, possibilités et limites. In: Neyret, Régis (dir.). Le patrimoine atout du developpement. Lyon: Centre J. Cartier/ Presses Univ. de Lyon, 1992, p. 49 e segs.

LARKHAM, P. Conservation and the City. London; Routledge, 1996.

LE GOFF, Jacques. Por amor às cidades: conversações com Jean Lebrun. São Paulo: Unesp, 1988.

LÉVI-STRAUSS, Claude. Tristes trópicos. São Paulo: Companhia das Letras, 1996.

MACEDO, Sílvio Soares. Paisagismo e paisagem introduzindo questões. In: Paisagem e Ambiente - Ensaios V. São Paulo: FAUUSP, 1994, p. 49-57.

MARX, Murillo. Cidade brasileira. São Paulo: Melhoramentos/Universidade de São Paulo, 1980.

MOESCH, Marutschka. A produção do saber turístico. São Paulo: Contexto, 2002.

MOSCOVICl, Serge. Essai sur l'histoire humaine de la nature. Paris: Flammarion, 1977.

PIRES, Mário Jorge. Lazer e turismo cultural. São Paulo: Manole, 2001.

RÉMY, Jean; VOYÉ, Liliane. A cidade: rumo a uma nova definição. Lisboa: Afrontamento, 1994.

ARDS, G.; BONINK, C. A. M. European Cultural Tourism Markets. Journal of Vacation Marketing, vol. 1, n.o 2, p. 173-180, 1995.

RODRIGUES, Adyr Balastreri. Turismo e espaço: rumo a um conhecimento transdisciplinar. 3. ed. São Paulo: Hucitec, 2001.

RUSCHMANN, Doris Van de Meene. Turismo e planejamento sustentável: a proteção do meio ambiente. 3. ed. Campinas: Papirus, 1997.

SANTOS, Milton. A natureza do espaço: técnica e tempo, razão e emoção. São Paulo: Hucitec, 1996.

A urbanização desigual: a especificidade do fenômeno urbano em países subdesenvolvidos. Petrópolis: Vozes, 1982.

-_. O espaço do cidadão. São Paulo: Nobel, 1998.

SERRANO, Célia; BRUHNS, Heloísa; LUCHIARI, Maria Tereza (orgs.). Olhares contemporâneos sobre o turismo. Campinas: Papirus, 2000.

SIMÃO, Maria Cristina Rocha. Preservação do patrimônio histórico em cidades. Belo Horizonte: Autêntica, 2001.

TELFER, Elisabeth. A filosofia da "hospitabilidade". In: LASHLEY, Conrad; MORRISON, Alison (orgs.). Em busca da hospitalidade: perspectivas para um mundo globalizado. Trad. Carlos David Szlak. Barueri-SP: Manole, 2004.

TURNER, Frederick. $O$ espírito ocidental contra a natureza. Trad. José Augusto Drummond. Rio de Janeiro: Campus, 1990. 
YÁZIGI, Eduardo. A alma do lugar: turismo planejamento e cotidiano. São Paulo: Contexto, 2002a.

; CARLOS, Ana Fani Alessandri; CRUZ, Rita de Cássia da. Turismo, espaço, paisagem

e cultura (orgs.). 3. ed. São Paulo: Hucitec, 2002b.

Pós-Doutor pela EHESS (França), Doutor em História pela Universidade Nova de Lisboa e Doutor em História pela USP. Professor do Programa de Mestrado de Arquitetura e Urbanismo e da Graduação em Turismo da Universidade São Judas Tadeu. É pesquisador CNPq e FAPESP.

Rua Dias Leme, 134 ap.64 -CEP 03118-040-Mooca-São Paulo-SP assuncao@prestonet.com.br 